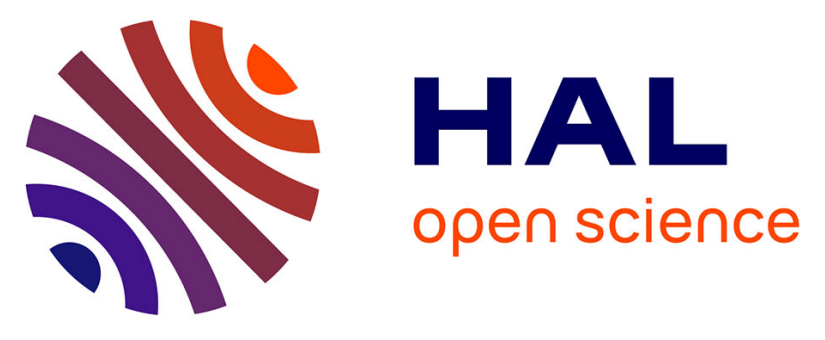

\title{
Владимир Андреевич Успенский (27.11.1930-27.06.2018)
}

Alexander Shen, Сергей Иванович Адян, Sergei Ivanovich Adian, Николай

Николаевич Андреев, Nikolai Nikolaevich Andreev, Лев Дмитриевич

Беклемишев, Lev Dmitrievich Beklemishev, Сергей Савостьянович Гончаров,

Sergey Savostyanovich Goncharov, Юрий Леонидович Ершов, et al.

\section{To cite this version:}

Alexander Shen, Сергей Иванович Адян, Sergei Ivanovich Adian, Николай Николаевич Андреев, Nikolai Nikolaevich Andreev, et al.. Владимир Андреевич Успенский (27.11.1930-27.06.2018). Russian Mathematical Surveys, 2019, 74 (4(448)), pp.165-180. 〈10.4213/rm9875〉. 〈lirmm-02337629〉

HAL Id: lirmm-02337629

https://hal-lirmm.ccsd.cnrs.fr/lirmm-02337629

Submitted on 29 Oct 2019

HAL is a multi-disciplinary open access archive for the deposit and dissemination of scientific research documents, whether they are published or not. The documents may come from teaching and research institutions in France or abroad, or from public or private research centers.
L'archive ouverte pluridisciplinaire HAL, est destinée au dépôt et à la diffusion de documents scientifiques de niveau recherche, publiés ou non, émanant des établissements d'enseignement et de recherche français ou étrangers, des laboratoires publics ou privés. 


\section{Владимир Андреевич Успенский (27.11.1930-27.06.2018)}

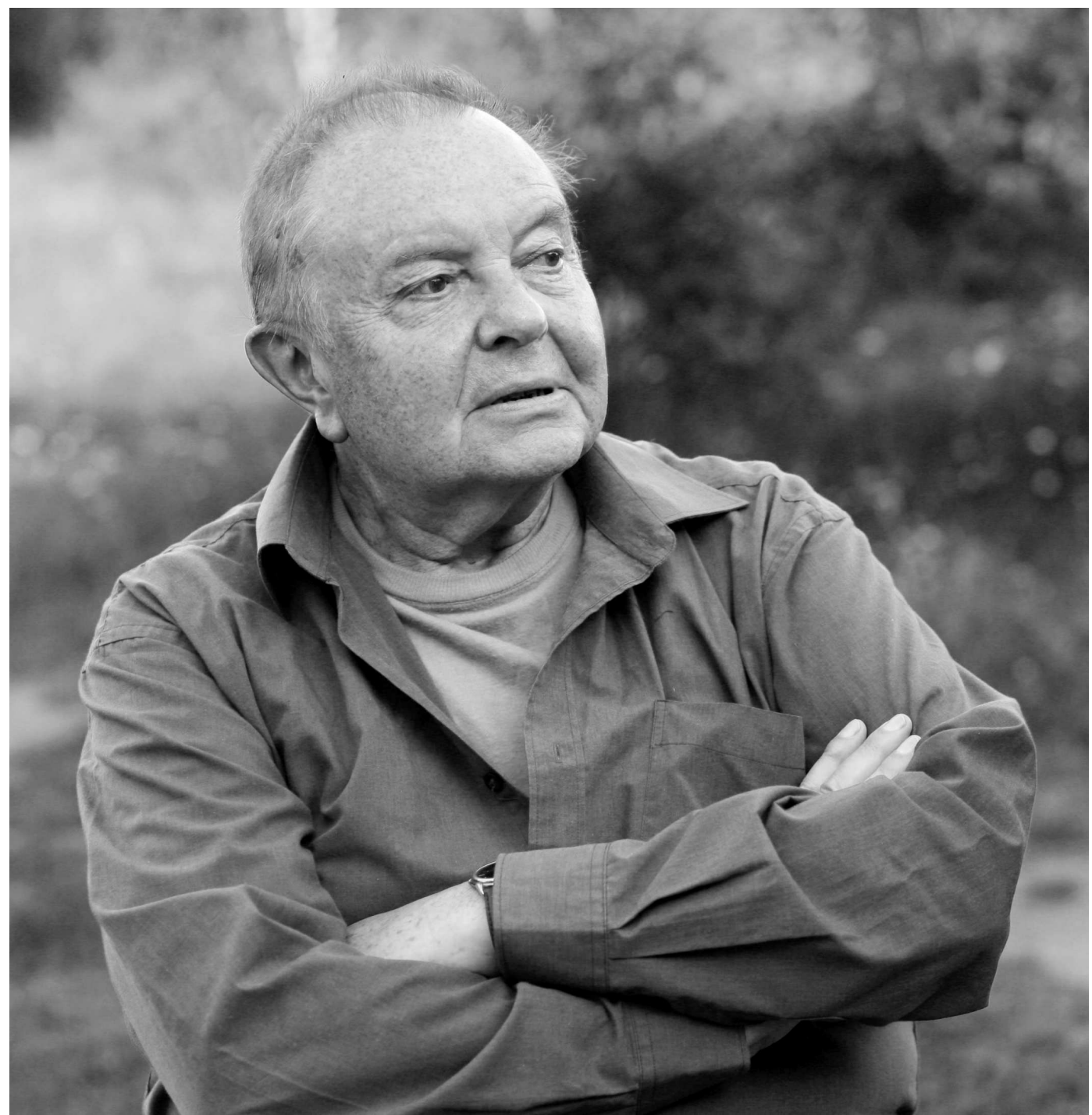

Сам жанр журнала "Успехи математических наук" предполагает обзор прежде всего математических результатов Владимира Андреевича Успенского. Однако вся его личность и деятельность обязывают к более широкому взгляду на вещи. Владимир Андреевич был выдающимся математиком, и это проявлялось в различных сферах его деятельности и её результатах и вне математики. Об этих сферах также будет идти речь в нашем обзоре. При жизни В.А. Успенский обходился без юбилейных статей в "Успехах". Это делает особенно важным опубликовать, хотя и с опозданием, его биографию как учёного в УМН.

DOI: https://doi.org/10.4213/rm9875 


\section{Семья}

Отец математика, Андрей Васильевич Успенский (22.06[05.07].1902-03.05.1978) был драматургом, временами его пьесы пользовались значительным успехом. Мать Владимира Андреевича - Густава Исааковна (урождённая Меклер, 1905-1988) была переводчицей пьес с французского (также она адаптировала некоторые произведения для театра). Успенский пишет: "Все доходы нашей семьи были связаны с театром: и автору пьесы, и переводчику положен некий процент от продажи билетов". Рассказ об отце и ссылки на источники в интернете есть в разделе "Успеня" в [30; кн. 5, c. 41-44]. О матери информация скудна.

Как показало время, связь Владимира Андреевича с литературой не прерывалась, одним из её завершений является "пятикнижье" [30], о котором будет упоминаться в следующих разделах нашего текста. Имелась она и в бытовом отношении: последние десятилетия своей жизни, с 1962 г., Успенский жил в "писательских домах на Аэропорте", конкретно - в кооперативном доме "Советский писатель" (см. [30; кн. 5, c. 642-655]). Конечно, для поездок в МГУ это было не очень удобно. Правда, при этом второе его место работы (по совместительству) - Всесоюзный институт научной и технической информации ${ }^{1}$ - было, как сейчас говорят, "в шаговой доступности”, т. е. Успенский ходил туда пешком (расстояние около двух километров). Поблизости от квартиры Успенского, во втором корпусе кооператива "Драматург", живёт ближайший друг последних лет жизни Успенского - Людмила Викторовна Ардова, вместе со своим супругом о. Михаилом (книги которого и дружбу с которым Владимир Андреевич очень ценил).

Владимир Андреевич был женат один раз - на Светлане Марковне Успенской (урождённой Киселевской, 06.10.1930-15.11.1980), с которой он познакомился 28 сентября 1948 г. Светлана Марковна закончила МГУ по специальности "история искусств". У Успенских 30 января 1959 г. родился их единственный ребёнок Владимир. Сейчас он, ученик А. В. Архангельского, работает профессором математики университета Огайо (Атенс, США), среди его математических интересов на сайте университета указаны функциональный анализ, динамические системы, общая топология и топологическая алгебра.

Брат Владимира Андреевича - Борис Андреевич Успенский (род. 01.03.1937) доктор филологических наук (1972), профессор МГУ (с 1977 г.) и Неаполитанского Восточного университета. В настоящее время заведует Лабораторией лингвосемиотических исследований НИУ “ВШЭ”. Занимается проблемами семиотики, теории языка (в том числе типологии), славянской филологии (в том числе истории русского и церковнославянского языков), литературоведения (поэтики) и искусствознания, истории русской церкви. В. А. Успенский о нём пишет: “... как филолог и историк культуры он хорошо известен как в России, так и за рубежом".

\section{Начало математической биографии}

Весной 1945 г. семиклассник Володя Успенский, придя на публичную лекцию для школьников, разговорился со студентом пятого курса мехмата Женей Дынкиным [Е. Б. Дынкин], который пригласил его в следующем году на свой кружок для восьмиклассников. В 1946 г. восьмиклассник Успенский получил первую премию на IX московской математической олимпиаде, а через год (перепрыгнув, по совету Дынкина, через класс) - вторую премию на X московской математической олимпиаде. Эти обстоятельства, видимо, оказали значительное влияние на всю дальнейшую жизнь Владимира Андреевича.

\footnotetext{
${ }^{1}$ ВИНИТИ; на работе Успенского там, несмотря на её важность, в данном обзоре мы не сможем остановиться подробнее в силу ограниченности места.
} 


\section{Математика}

Гармонические функции. В 1947 г. Володя Успенский поступил на механико-математический факультет Московского университета, с которым оказалась связана вся его дальнейшая жизнь. Младшекурсником он продолжал ходить на (теперь уже студенческий) кружок Дынкина, и одним из результатов этого была статья [3]. Там он предложил элементарное изложение основных свойств гармонических функций, основанное на таком наблюдении: угол, под которым виден фиксированный отрезок из переменной точки, является гармонической функцией этой точки в том смысле, что для него верна теорема о среднем, и функция эта является ступенчатой на любой окружности, проходящей через концы отрезка.

Теория вычислимости. В 1949 г. произошло важнейшее в жизни В. А. Успенского событие. Вот как он описывает его в разделе "Моё ученичество у Колмогорова" своих воспоминаний об А. Н. Колмогорове [30; с. 116-117]:

Меня одолевали сомнения, смогу ли я стать профессиональным математиком; $\langle\ldots\rangle$ я поделился этими сомнениями с Колмогоровым. . Андрей Николаевич, выяснив мои пристрастия, подарил мне оттиски трёх своих знаменитых работ по математической логике и теории множеств $\langle\ldots\rangle$ он сделал надпись: "Володе Успенскому в час его сомнений насчёт своей математической судъбъ. 22-I-1950. А. Колмогоров". Тогда же, не без некоторой торжественности, я был произведён в ученики и мне была назначена тема занятий: рекурсивные функции. Мне было сообщено, что это важная вещь, но что в нашей стране они мало кому известны. 〈...〉 Мне были выданы на время иностранные журналы со статьями Клини и других для самостоятельного изучения.

Результатом этого изучения и обсуждений с Колмогоровым стали работы Успенского по теории вычислимости (включая его дипломную работу [4] и диссертацию [8]).

Мы видим, как сочетание интуиций Успенского и Колмогорова привело Владимира Андреевича именно в математическую логику и теорию алгоритмов. Как нам кажется, дальнейшая математическая и научная судьба В. А. Успенского доказывает, что этот выбор был счастливым. Не будет преувеличением сказать, что без Успенского советская (российская) математическая логика (включая в неё теорию алгоритмов) была бы совсем другой: почти все, кто сейчас в России занимается логикой и теоретической информатикой, прямо или косвенно (как ученики, коллеги, коллеги учеников и ученики коллег, читатели книг и статей) испытали на себе существенное влияние Успенского. Кроме того, лингвистика (о которой речь пойдёт дальше) из математических дисциплин, конечно, находится в соседстве именно с логикой.

Относительная вычислимость. Относительная вычислимость, или вычислимость с оракулом, использовалась Э. Постом и А. Тьюрингом. Но и у Тьюринга, и у Поста определения были "машинно-зависимыми", т. е. получались модификацией конкретной вычислительной модели с добавлением возможности запроса "оракула". Успенский в своей дипломной работе [4] впервые предложил машинно-независимое определение, которое использует не конкретную вычислительную модель, а лишь задаваемый этой моделью класс вычислимых функций, потребовав, чтобы стратегия диалога с оракулом была вычислимой. Он доказал, что это определение равносильно другим, в том числе определению в терминах частично рекурсивного замыкания. Теперь машинно-независимое определение относительной вычислимости является стандартным (см., например, учебник Х. Роджерса [32]), но определение Успенского имеет и то преимущество, что оно, в отличие от определения из [32], без изменений переносится на частичные функции в качестве оракулов. 
Машины Колмогорова-Успенского. В уже упомянутой дипломной работе Успенского [4] излагается модель вычислений, предложенная А.Н. Колмогоровым и известная теперь как "машины Колмогорова-Успенского" [10]. В знаменитом тезисе Чёрча-Тьюринга речь идёт не о том, что всякий алгоритм можно представить как алгоритм работы машины Тьюринга. Там утверждается, что всякая вычислимая функция (т. е. функция, задаваемая алгоритмом) может быть вычислена некоторой машиной Тьюринга. Колмогоров же вместе с Успенским предлагают математический объект, претендующий на неформально понимаемое моделирование любого алгоритма с локальным преобразованием информации на каждом шаге. Сам Колмогоров в отзыве на работу Успенского пишет: "В известном смысле слова этот результат можно рассматривать как 'обоснование' прежних определений, так как в моём определении становится особенно ясной основная идея алгоритмической вычислимости, которая отличается от вычислимости обыкновенным реальным счётным механизмом только неограниченным объёмом 'запоминающего устройства' механизма”.

Впоследствии А. Шёнхаге рассматривал другую модель, близкую к машинам Колмогорова-Успенского, понимая под связями скорее ссылки, чем какие-то почти физические соединения, как в первоначальном замысле Колмогорова. Подробное обсуждение см. в [21].

Вычислимые операции. Следующий цикл результатов В. А. Успенского относится к 1955 г. и вошел в его кандидатскую диссертацию [8].

Вычислимость с оракулом можно рассматривать и с точки зрения операций над функциями (а также над множествами): функции-оракулу ставится в соответствие функция, вычисляемая данной машиной при использовании этого оракула. Успенский назвал такие операции вычислимыми и предложил их топологическую характеризацию в [6]. Мы приведём определения для случая множеств, где они технически проще. $\mathrm{B}$ множестве $\mathcal{P}(\mathbb{N})$ всех подмножеств натурального ряда базой топологии объявляются надмножества конечных множеств. Непрерывное отображение $F: \mathcal{P}(\mathbb{N}) \rightarrow \mathcal{P}(\mathbb{N})$ называется вычислимой операцией, если множество всех пар $\langle X, n\rangle$, где $X$ - конечное множество, а $n$ - натуральное число, принадлежащее $F(X)$, перечислимо. Аналогично определяются непрерывные и вычислимые операции на пространствах частичных функций. Интуитивный смысл требования непрерывности состоит в том, что каждое значение результирующей функции определяется некоторым конечным числом значений функции-аргумента. Относительная вычислимость $f$ с оракулом $g$ означает существование вычислимой операции, переводящей $g$ в $f$.

Сводимость по перечислимости и другие сводимости. Определив вычислимые операции, Успенский (в работах 1955 г. [6], [7] и своей диссертации [8]) объясняет в их терминах сводимость по перечислимости для множеств натуральных чисел: множество $A$ сводится по перечислимости к множеству $B$, если существует вычислимая операция, отображающая $B$ в $A[6]$. Это определение уточняет интуитивную идею о сводимости задачи перечисления множества $A$ к задаче перечисления множества $B$. В его терминах можно определить и относительную вычислимость функций: функция $f$ вычислима относительно (всюду определённой) функции $g$, если график функции $f$, т. е. задающее её множество пар, сводится по перечислимости к графику функции $g$. Понятие сводимости по перечислимости было переоткрыто Х. Роджерсом (и опубликовано в 1959 г. в [34] со ссылкой на записки лекций Роджерса 1957 г.).

26 июня 1956 г. на Третьем всесоюзном математическом съезде Успенский сделал обзорный доклад "Об алгоритмической сводимости". Он пишет в [30; с. 905-906]: "я рассказывал о четырёх видах сводимости и связях между ними. Это сводимость по вычислимости, состоящая в сведении вычисления одной функции к вычислению 
другой. Это сводимость по разрешимости, состоящая в сведении задачи построения разрешающего алгоритма для одного множества к задаче построения разрешающего алгоритма для другого множества. Это сводимость по перечислимости, состоящая в сведении перечисления одного множества к перечислению другого. Это сводимость проблем, состоящая в сведении решения одной проблемы к решению другой. 〈..〉 В 1955 году интересную разновидность проблем ввёл ученик Колмогорова Ю. Т. Медведев; он же определил понятие сводимости для таких проблем".

Нумерации, главные нумерации. Успенский в [7] опубликовал (предложенное Колмогоровым на семинаре по рекурсивной арифметике) определение понятия нумерации и сводимости нумераций и ввёл понятие главной нумерации для перечислимых множеств и вычислимых функций.

До этого утверждения о свойствах вычислимых функций, связанных с их "программами" (скажем, о возможности алгоритмического преобразования программ), формулировались в терминах конкретной вычислительной модели (программ машин Тьюринга, кодов заданий частично рекурсивных функций и т. д.).

Выбор модели важен, поскольку она задаёт нумерацию вычислимых функций: "номером" функции является её программа. (Сегодня мы бы говорили скорее об "именах" функций, которыми могут быть строки символов, чем об их "номерах", но в то время обычно рассматривалась вычислимость функций с числовыми аргументами.)

Успенский понял, что вместо конкретной нумерации, связанной с той или иной вычислительной моделью, можно рассматривать любую нумерацию, удовлетворяющую некоторым естественным требованиям. Он назвал такие нумерации главными.

Нумерация называется главной, если (1) она вычислима (по программе и аргументу может быть вычислен результат применения программы к аргументу) и (2) любая другая вычислимая нумерация к ней сводится (по номеру в другой нумерации можно эффективно получить номер в главной нумерации).

Понятие главной нумерации было переоткрыто Роджерсом в [41] под названием "Gödel numbering".

Алгоритмические свойства классов множеств и функций. 1955-1956 гг. оказались весьма плодотворными для рассматриваемой области теории алгоритмов (исторически называемой также теорией рекурсии), в частности, именно в этот период А. А. Мучником и Р. М. Фридбергом был открыт метод приоритета. До этого, в [39] Г. Райс рассмотрел вполне перечислимые классы перечислимых множеств, т. е. такие классы перечислимых множеств, для которых множество всех программ всех множеств этого класса перечислимо, и сформулировал гипотезу о том, что всякий такой класс состоит из всех надмножеств множеств из некоторого перечислимого семейства конечных множеств. Это утверждение составляет теорему 5 в работе Успенского 1955 г. [7]. Детальное доказательство теоремы 5 приводится в его диссертации [8]. Указанное утверждение также доказано в статье Райса 1956 г. [40], где говорится, что независимо тот же результат получили Р. Мак-Нотон, Дж. Майхилл и Н. Шапиро (ссылки на их работы не приводятся, кроме ссылки на краткую заметку Майхилла [37]). Эта теорема обычно называется в англоязычной литературе теоремой Райса-Шапиро. Из указанной теоремы 5 Успенского вытекает также, что никакое нетривиальное свойство вычислимой функции нельзя алгоритмически распознать по его номеру. В англоязычной литературе это утверждение обычно называют теоремой Райса, но в российских публикациях и лекциях часто соблюдается приоритет Успенского.

Из той же теоремы вытекает аналогичное утверждение для перечислимых множеств, и оно действительно было опубликовано Райсом в 1953 г. [39].

При этом главным результатом Успенского этого периода является, видимо, так называемая теорема Успенского-Майхилла-Шепердсона (теорема 3 в цитате далее) 
о том, что вычислимые преобразования программ продолжаются до вычислимых операций над функциями, см. [7], [38]. (Ключевым шагом в ее доказательстве является упомянутая выше теорема 5.) В своих воспоминаниях [30; кн. 5, с. 905-907, 912] Успенский пишет о представлении своих результатов на Третьем всесоюзном математическом съезде (1956):

Наименование моего доклада 2 июля было "Понятие программы и вычислимые операторы", а сообщения 3 июля - "Вычислимые операции, вычислимые операторы и конструктивно-непрерывные функции". Доклад и сообщение были тесно связаны тематически.

В сообщении 3 июля был изложен (разумеется, без доказательства) результат, который я считаю своим главным математическим результатом $\langle\ldots\rangle$

Теорема 3. Пусть функиия $g$ с натуральньми аргументами и значениями обладает следующим свойством. Если $m$ и $n$ служат программами одной и той же вычислимой функции от $s$ аргументов, то $g(m)$ и $g(n)$ также служат программами одной и той же функияи от одного аргумента. Тогда существует вычислимый оператор $V$ со следующим свойством. Для всякой функции $\theta$ с программой $n$ значением $V(\theta)$ оператора $V$ на функиии $\theta$ является функция с программой $g(n)$.

Философский комментарий. Семиотический смысл теоремы 3 таков: "хорошее" вычислимое преобразование имён сопровождается вычислимым преобразованием соответствующих объектов.

К сожалению, публикации Успенского 1950-х годов представляют собой краткие заметки в Докладах Академии наук СССР и резюме докладов, где приводятся только формулировки теорем и лемм, используемых в их доказательствах. Сами доказательства были опубликованы в упомянутой дипломной работе и в кандидатской диссертации Успенского [8], которая хотя формально и была доступна (её можно было заказать и получить в нескольких библиотеках СССР), но вряд ли повлияла на дальнейшее развитие области. Да и статьи [6], [7], [9] с кратким изложением, видимо, остались неизвестными вне СССР. Позже книга Успенского [13] (учебник по теории вычислимых функций, который стал докторской диссертацией Успенского) была переведена на французский язык - но, к сожалению, в неё не вошли его результаты о вычислимых операциях и операторах.

Осмысление основных открытий и приложений теории алгоритмов. Ургенч. В 1979 г. Андрей Ершов и Дональд Кнут организовали симпозиум "Алгоритмы в современной математике и её приложениях", посвящённый аль-Хорезми, на родине Аль-Хорезми в городе Ургенч (Узбекистан). Предложение Андрея Петровича Ершова сделать "заглавный доклад" на этом симпозиуме оказалось для Успенского побудительной причиной осознать свою роль как "осмыслителя" своей области науки и представить эту область коллегам - ведущим мировым специалистам в теории и практике алгоритмов. Помимо Ершова и Кнута, участниками симпозиума были, в частности, Х. Земанек, С. Клини, А. ван Вейнгаарден, М. Патерсон, Ф. Штрассен, Ю. Л. Ершов, С. С. Лавров, Ю. И. Манин, Ю. В. Матиясевич, Н. А. Шанин, Г. С. Цейтин.

То значение, которое, в исторической перспективе, В. А. Успенский придавал своему участию в этом симпозиуме, доказывается, в частности, тем, что материалам, связанным с ним, он посвятил несколько десятков страниц своих воспоминаний [30; кн. 5, с. 566 и сл.]. Работа над докладом "Что дает теория алгоритмов? (Основные открытия в области теории алгоритмов за последние полвека)" Успенского, с его соавтором А.Л. Семёновым, при участии А. Шеня, началась в мае 1979 г. и была 
основным делом Владимира Андреевича вплоть до 17 сентября 1979 г., когда доклад был сделан. Доклад был именно его жанром осмысления всей области, к которой относились и его собственные исследования. Работа велась крайне напряжённо, со свойственной Владимиру Андреевичу скрупулёзностью, поиском и тщательным прочтением первоисточников и т. п. Вот один пример, который мы цитируем по его воспоминаниям [30; кн. 5, с. 592]: "Итак, я искал точку во времени. Окончательный вывод, к которому я пришёл, состоял в том, что впервые понятие алгоритма, хотя алгоритмом и не названное, появилось в 1912 году в мемуаре Бореля 'Исчисление определённых интегралов' ". После симпозиума продолжилась работа по подготовке текста доклада для публикации и затем его расширенного варианта в виде книги [21].

В ходе работы над докладом были прояснены многие концептуальные вопросы. Одним из результатов Симпозиума и Доклада стала совместная работа В. А. Успенского в последующие годы вместе с молодыми математиками - Н. К. Верещагиным, Ан. А. Мучником, А. Л. Семёновым, А. Х. Шенем. Она относилась, в первую очередь, к сложности конечных объектов.

Сложность конечных объектов. Понятие сложности конечного объекта было в Ургенчском докладе отнесено к числу основных открытий теории алгоритмов. Это открытие было сделано в последних математических работах учителя Успенского - Колмогорова, опубликованных в 1963-1969 гг. В докладе был предложен подход к классификации различных видов сложности (или, как предпочитал говорить Успенский, "энтропии") для конечных объектов, определённых к тому времени (простая, префиксная, условная, монотонная энтропии, а также энтропия разрешения).

Итогом деятельности Успенского по осмыслению работ Колмогорова по сложности конечных объектов, лёгших в основу алгоритмической теории информации, был совместный доклад Колмогорова и Успенского [22], прочитанный Успенским в сентябре 1986 г. в Ташкенте на Всемирном конгрессе Общества Бернулли. Успенский писал: "K сожалению, Андрей Николаевич уже не мог не только ознакомиться с текстом, но даже обсуждать доклад в процессе его подготовки. Разумеется, он полностью основан на его идеях".

Алгоритмической теории информации посвящены также обзор [23] и монография [29]. Популярная лекция (для студентов-младшекурсников), посвящённая различным определениям случайности, была прочитана Успенским на летней школе "Современная математика" в Дубне в 2005 г.; материалы этой лекции были изданы [26] и вошли в качестве приложения в монографию [29].

До сих пор остаётся открытым вопрос, поставленный Успенским, Семёновым и Мучником в [24], о том, совпадают ли понятия случайности по Мартин-Лёфу и случайности относительно вычислимых немонотонных игр ("непредсказуемости"). См. подробнее в [26], [29].

Конструктивизация объектов классической математики. Идея о том, что можно понимать математические определения и утверждения конструктивно, была известна давно ("интуиционизм" Брауэра и его последователей, а позже "конструктивизм" Маркова и его учеников). В частности, утверждения вида "для всех $x$ существует такой $y$, что..." при конструктивном понимании предполагают, что существует некоторый способ получения этого самого "существующего" у по любому данному значению $x$. Последовательное проведение такой точки зрения требует изменения как логики математических рассуждений, так и самого их предмета. Скажем, с точки зрения школы Маркова вместо действительных чисел нужно рассматривать "конструктивные действительные числа" - пары алгоритмов (один алгоритм вычисляет последовательность приближений, другой задаёт регулятор сходимости этой последовательности). 
Успенский стоял на другой точке зрения, при которой "классическая математика" не исчезает, заменяясь конструктивной, а обогащается: конструктивные (вычислимые, эффективные) объекты выделяются среди классических, и содержательные рассуждения о них проводятся обычными математическими средствами. Например, в поле действительных чисел можно выделить (счётное вещественно замкнутое) подполе вычислимых действительных чисел, взяв те числа, для которых существует вычислимая вычислимо сходящаяся последовательность рациональных чисел. В [12] разобраны варианты определений вычислимых действительных чисел, исходящие из различных классических конструкций (сечения Дедекинда, фундаментальные последовательности, бесконечные дроби и др.), и показано, что хотя они все приводят к одному и тому же подполю поля действительных чисел, но задаваемые ими нумерации вычислимых действительных чисел не все "одинаково хороши".

В [13] разобраны варианты конструктивизации другого классического понятия бесконечного множества натуральных чисел, и показано, что разные варианты классических определений приводят к неэквивалентным вычислимым аналогам (в одних случаях получаются множества, не являющиеся иммунными, в других - множества, не являющиеся гипериммунными, см. подробнее в [13]).

Машинно-независимое изложение теории алгоритмов. Теорема Гёделя с точки зрения теории алгоритмов. Традиционное построение изложения теории алгоритмов состоит в том, что предъявляется какая-то формальная модель вычислений. Но в дальнейшем доказательства почти не ссылаются на эту модель, а опираются в основном на интуитивные представления о том, что такое алгоритм. (Среди очень немногих исключений - монография А. А. Маркова [35], где алгоритмы действительно формально строятся.)

Успенский показал (см. [15]), что важные факты теории алгоритмов можно доказать в рамках традиционной математики (в действительности, малой части теории множеств), не прибегая ни к какой формальной модели, а только используя некоторые свойства вычислимых функций, перечислимых и разрешимых множеств, формулируемые как "аксиомы”. Опишем эти аксиомы неформально, для экономии места.

- Аксиома протокола утверждает, что для всякого алгоритма $A$ существуют разрешимое множество всех "протоколов" вычислений и эффективный способ извлечения из каждого из них исходного данного и результата вычисления.

- Аксиома программы утверждает, что есть один универсальный алгоритм с двумя аргументами, который позволяет получить любую вычислимую функцию путём фиксации первого аргумента (программы вычисления).

Помимо этих аксиом используются утверждения о вычислимости конкретных функций и о сохранении вычислимости при каких-то конструкциях - скажем, о вычислимости композиции вычислимых функций. Указанная аксиоматизация теории алгоритмов позволяет строго обосновать известное наблюдение о том, что большинство результатов теории алгоритмов "релятивизуются", т. е. сохраняют силу, если вычислимые функции заменить функциями, вычислимыми с некоторым фиксированным оракулом (в качестве которого можно взять множество или всюду определённую функцию). Успенский поставил вопрос, полностью ли это наблюдение объясняет возможность релятивизации. Ответ на него был получен А. Х. Шенем [42]. Дальнейшим продвижением этой линии можно считать работу Андрея Мучника [36], где доказывается, что общая теория алгоритмов есть теория ровно одной структуры (главной универсальной нумерации), а утверждения, истинные при всех достаточно сильных релятивизациях, можно характеризовать в терминах существования выигрышной стратегии в некоторой (машинно-независимой) игре.

Успенский использует указанные аксиомы в своём изложении доказательства теоремы Гёделя о неполноте арифметики в контексте теории алгоритмов, и в связи с этим 
ему нужна ещё одна аксиома, означающая, что всякую вычислимую функцию можно описать на языке логики и арифметики (сложения и умножения). Разумеется, если доказывать аналог теоремы Гёделя для более богатой, чем арифметика, теории, соответствующее утверждение становится очевидным. Например, можно заранее позаботиться, чтобы в языке было легко описать работу машины Тьюринга.

\section{Научно-организационная роль Успенского в математической логике}

Выше уже упоминались выступления незадолго до этого ставшего кандидатом наук 25 -летнего В. А. Успенского на Третьем всесоюзном математическом съезде. Но замечательно, что именно по инициативе Владимира Андреевича съезд принял резолюцию о создании кафедры математической логики на мехмате МГУ (детально история рассказана в [30; кн. 5, с. 897 и сл.]). Кафедра была создана при непосредственном участии П.С. Новикова и С.А. Яновской в 1959 г., и её возглавил член-корреспондент АН СССР Андрей Андреевич Марков. Здесь нет возможности останавливаться на диалоге и полемике между молодым В. А. Успенским и заведующим кафедрой А. А. Марковым. Отголоски этого диалога нашли отражение в работах Успенского, упомянутых в разделе "Конструктивизация объектов классической математики" данного обзора.

Но существенно, что при очень жёсткой методологической позиции видного математика Маркова, говорившего "я этого не понимаю" (в смысле - "не согласен", "не признаю") о большей части математики, на кафедре развивался широкий спектр исследований (в том числе и "не понимаемых" Марковым). Роль Успенского в жизни кафедры и тогда, и в дальнейшем была абсолютно критической. Большинство работников кафедры были его учениками, или учениками его учеников, или находились под его решающим влиянием. Владимир Андреевич был назначен заведующим кафедрой математической логики МГУ (сегодня - кафедра математической логики и теории алгоритмов) только в 1993 г., но его роль во все предшествующие годы далеко выходила за границы заместителя заведующего (его официальная должность начиная ещё со времён Маркова). При этом Успенский в научно-организационной иерархии ощущал себя именно профессором МГУ, не стремился к академическим званиям, правительственным наградам и премиям (и никогда их не получал).

Мы надеемся, что Кафедра во многом останется Кафедрой В. А. Успенского не только в истории, но и в будущем.

Работы Успенского - и, даже в большей степени, его преподавательская и просветительская деятельность (о которой см. ниже) - повлияли на развитие теории алгоритмов в СССР и России. В частности, определение понятий нумерации и сводимости нумераций было одним из источников теории нумераций в СССР (школа А. И. Мальцева и Ю. Л. Ершова в Новосибирске).

\section{Лингвистика и другая не-математика, философия, история науки}

Попыткой подведения итогов своей жизни вне математики для В.А. Успенского [30] стало, в значительной степени, издание его "Трудов по нематематике", с характерным для его чувства слова названием. "Труды" включают следующие области:

- филология (рассуждения о литературных текстах, их понимании и интерпретации);

- лингвистика;

- философия, основания науки;

- история: "Воспоминания и наблюдения" (совершенно самостоятельный раздел, который разрастался по мере появления других томов). 
Пожалуй, чем-то объединяющим эти направления для В. А. Успенского был его постоянный пристальный интерес, уважение и любовь к слову, вера в его важность. Уже совсем за пределами данного обзора находится поэтическое творчество Владимира Андреевича. В данном контексте укажем лишь, что в поэзии он, пожалуй, особенно любил такой жанр, как пародия и подражание. Знаменитая пародия "Курочка Ряба" (см. [кн. 4, с. 25]), которая попала в фильм "Когда я стану великаном" - это знак из детства. Многое из того, что Владимир Андреевич писал в стихотворной форме иронические подражания, и этот выбор не случаен, это выбор исследователя, ведь хорошо известно, что пародия - это инструмент понимания текста через остранение, очень эффективный способ проникнуть в текст с неожиданной стороны. Владимир Андреевич этим искусством владел в совершенстве. Его большая статья про словесные квипрокво [30; кн. 4, с. 254] - это блестящая демонстрация того, как можно понять человеческую психологию и историю цивилизации через разные типы путаниц, смешений, "опечаток". Его "Воспоминания и наблюдения" [30; кн. 5] и устные истории, непревзойдённым мастером которых он был (и которые, к сожалению, лишь в незначительной степени сохранены в аудио- и видеозаписи), являют собой примеры и исторического исследования, и популяризации такого исследования, и интереса к истории человечества в целом.

Научная деятельность В.А. Успенского неотделима от той, что называется у нас обычно "научно-организационной". А это была уникальная в нашей стране работа по созданию современной научной школы в области лингвистики, ставшей при этом не локальным, а мировым явлением.

Здесь нет возможности детально описывать создание в МГУ Отделения теоретической и прикладной лингвистики [30; кн. 3, с. 330 и сл.] или защиту Андреем Анатольевичем Зализняком кандидатской диссертации, в ходе защиты преобразованной силами Успенского в докторскую (а также существенную роль, которую в организации этой докторской защиты сыграли другие ученики Колмогорова - Р. Л. Добрушин и, через него, А. С. Монин) [30; кн. 5, с. 998 и сл.]. В научном же плане В. А. Успенский привлек потенциал своего учителя А.Н. Колмогорова, в ответ на обращение Успенского поставившего перед исследователями языка вопросы о возможности эффективного определения двух понятий: из области грамматики (падеж) и из области стиховедения (ямб). Первой лингвистической работой В. А. Успенского была статья "К определению падежа по А.Н. Колмогорову" (1957 г., см. [30; кн. 5, с. 998 и сл.]). Как и другие его лингвистические работы 1950-1960 гг., это своего рода демонстрация для будущих лингвистов: “строгой” аксиоматической лингвистики ещё нет, но если бы она была, то она была бы такой - попробуйте работать вот так. Продолжением этой интенции во многом стала важнейшая книга А. А. Зализняка "Русское именное словоизменение" (1967, [43]), где обсуждается так называемая "процедура Колмогорова" для определения количества падежей в произвольном языке, которую, конечно, следует называть "процедурой Колмогорова-Успенского", а за пределами книги, сегодня, это "процедура Колмогорова-Успенского-Зализняка". Далее, среди работ Успенского 1960-х годов: "Одна модель для понятия фонемы" (1964, см. [30; кн. 3, с. 77 и сл.]), "К проблеме транслитерации русских текстов латинскими буквами" (1967, см. [30; кн. 3, с. 202 и сл.]) и подробный отзыв о диссертации А.А. Зализняка, имеющий самостоятельное научное значение (1965, см. [30; кн. 3, с. 123 и сл.]).

Таким образом, в этот период важнейший вклад Успенского в лингвистику - это математическое моделирование лингвистических понятий, определение терминов, методологические рамки исследования языка. Вклад, пожалуй, прежде всего - в лингвистов, работающих, а главное - будущих. Успенский является воспитателем нескольких поколений российских лингвистов, видимо, в не меньшей степени, чем научные руководители их студенческих работ и диссертаций. 
В 1970-е годы Владимир Андреевич ведёт активный диалог с ведущими лингвистами страны в областях, где российская лингвистика тогда добивалась впечатляющих результатов. К такому диалогу, в частности, относятся "Замечания на полях статей Мельчука и Холодовича о понятии залога" (1975, см. [30; кн. 3, с. 228 и сл.]) и "К понятию диатезы" (1977, см. [30; кн. 3, с. 241 и сл.]). Сегодня это часть классической проблематики теории залога. В 1979 г. Успенский пишет знаменитую и, вероятно, самую провокационную свою статью "О вещных коннотациях абстрактных существительных". Проще всего было бы относиться к этой статье как к шутке, игре, своего рода пародии, обсуждающей, что с точки зрения русского языка "авторитет" - это на самом деле большой тяжёлый шар, который принято держать высоко над головой и следить за его устойчивостью. Однако сегодня эта статья рассматривается как одна из предтеч теории метафор и многих других направлений в теоретической семантике и не только. Возможно, следующая волна её влияния будет в сфере искусственного интеллекта.

И последняя в этом ряду - статья 1979 г., написанная в соавторстве с Е. В. Падучевой: "Подлежащее или сказуемое" (Семантический критерий различения подлежащего и сказуемого в биноминативных предложениях)" [30; кн. 3, с. 271-289]. Биноминативные предложения - это такие предложения, в которых нет глагола: "Горячка этот Иван Васильич" - знаменитый пример (из рассказа Житкова "Волы"), ставящий в тупик "школьную" лингвистику. Эта работа, тогда находившаяся на переднем крае русистики, и сегодня читается с интересом.

Одна из последних лингвистических работ Успенского "Субъективные заметки о неправильной норме" (2006, см. [30; кн. 3, с. 598-660]) - в каком-то смысле итоговая и для теоретической, и для прикладной лингвистики, и при этом обращённая к широкому кругу носителей языка, с характерным для Успенского просветительским пафосом.

Завершая лингвистический раздел нашего обзора, мы возвращаемся к роли В. А. Успенского как главного создателя современной российской теоретической лингвистики. Воспитание многих поколений лингвистов было бы невозможно без серьёзного математического компонента в их образовании. Содержание этого математического образования формировалось под прямым руководством Владимира Андреевича. Дело здесь совсем не в знании конкретных математических теорем и формул. Важен способ мышления, доказательства, коммуникации, стандарт достоверности и эксплицитности изложения.

И вот, как элемент привлечения в лингвистику детей, готовых к такому стилю мышления, в Москве возникает "Первая традиционная олимпиада по языкознанию и математике", впервые проведённая в 1964-65 учебном году [30; кн. 3, с. 146 и сл.]. (Читатель этих строк уже слышит голос Успенского в названии "Первая традиционная...".) Участники и призёры олимпиад составляли важную категорию студентов Отделения теоретической и прикладной лингвистики. Однако ограничиваться этой категорией было нельзя. И важным элементом отбора был серьёзный экзамен по математике для поступающих на это отделение (ключевой фигурой в этом экзамене был, конечно, Успенский, посвятивший этой проблематике и несколько публикаций, см. [30; кн. 3, с. 196 и сл.]).

K сожалению, в последние годы слово “лингвистика" в русском языке, в частности в сфере образования и науки, используется расширительно: стало выгодно и престижно говорить о лингвистических институтах и факультетах, имея в виду лишь обучение иностранным языкам или переводческое дело - весьма почтенное, но всё же очень косвенно пересекающееся с лингвистикой как научной теорией языка. Естественно, что практическое направление требует большого внимания, финансирования и т. д. Однако в нашей стране несколько раз возникала опасность поглощения фундаментальной лингвистической науки этим практическим направлением. 
Ключевым элементом такого поглощения и снижения уровня лингвистики могло бы стать изъятие математики из списка вступительных испытаний для поступающих на специальность "Фундаментальная и прикладная лингвистика" в случае, если бы эта специализация стала частью более общей - переводческой и методической. Благодаря инициативе и личному влиянию В.А. Успенского этого поглощения до сих пор удавалось избегать, а математика оставалась и как важнейший предмет изучения, и как часть вступительных испытаний. Преподавание самого Успенского на ОТиПЛе прекратилось в 2013 г. Но математика там осталась, и по сей день преподаётся, в основном, сотрудниками кафедры Владимира Андреевича. Совместная с ним работа в оргкомитетах и задачных комиссиях олимпиад оказала существенное влияние на общекультурное и лингвистическое мировоззрение десятков ведущих современных лингвистов, формально не учившихся у Владимира Андреевича, но ощущающих себя его учениками.

История становления лингвистики в нашей стране, роль Успенского в которой пунктиром намечена в настоящем обзоре, к счастью, описана самим Успенским в его воспоминаниях "Серебряный век структурной, прикладной и математической лингвистики в СССР. Как это начиналось (заметки очевидца)" [30; кн. 3, с. 293-471]. Несмотря на полноту, детальность и точность этого блестящего текста, он в принципе не может отразить все оттенки роли В.А. Успенского в отечественной и мировой лингвистике. Поэтому мы повторим ещё раз: он создатель, непосредственный участник, пропагандист, популяризатор

- современной научной парадигмы в отечественной лингвистике;

- уникальной системы лингвистического образования, а именно университетской подготовки теоретических лингвистов, которая существует и по сей день.

В силу этого В.А. Успенский оказал непосредственное влияние, в том числе - личное, на способ мышления, жизненную и научную карьеру нескольких тысяч людей, заметных в жизни России XX-XXI вв.

Просвещение, математическое образование, популяризация. Ещё будучи студентом, Успенский (вместе со старшим соавтором Евгением Борисовичем Дынкиным) написал книгу "Математические беседы" [4] по материалам математических кружков, где он сначала был участником, а потом руководителем (с этого мы начали наш обзор). В ней, в отличие от других книжек знаменитой серии "Библиотека математического кружка", задачи были разбиты на циклы, каждый из которых представлял собой изложение некоторой математической теории.

Успенский написал несколько популярных брошюр в серии "Популярные лекции по математике", никак не связанных с его собственными научными интересами: про применение механики в математике [11] и про треугольник Паскаля [14]. Впрочем, последняя брошюра затрагивает и логический вопрос: что означает решить комбинаторную задачу и почему нужно фиксировать список разрешённых операций (скажем, включив в него факториалы, но исключив обозначения для биномиальных коэффициентов). Две другие брошюры в этой серии ("Машина Поста" [16] и "Теорема Гёделя о неполноте" [17]) посвящены уже темам из математической логики и теории алгоритмов. Первая из них основана на занятиях с младшеклассниками, вторая, наоборот, написана на основе статьи в "Успехах математических наук" [15] и предполагает некоторую математическую культуру.

Популярному изложению "нестандартного анализа", где методы математической логики используются для математически корректного рассмотрения бесконечно малых и бесконечно больших величин, посвящена брошюра [18]; её расширенный вариант был опубликован затем издательством "Наука" [20].

Несколько лекций Владимира Андреевича на летних школах по математике и лингвистике в Дубне, к счастью, сохранились как видеозаписи (прежде всего благодаря 
Виталию Арнольду), и по ним (см. ссылки в [1], [2]) можно составить представление об Успенском как лекторе - хотя, конечно, в полной мере оценить его можно было только на университетских лекциях, особенно спецкурсах.

При этом просвещенческая проповедь Успенского была именно проповедью математики, а не "о математике". Он рассказывал простые вещи, но всерьёз, с определениями, примерами и доказательствами. Одна из его последних книжек [28] так и называется: "Простейшие примеры математических доказательств". Другая книжка [25] называется "Что такое аксиоматический метод?" - и там тоже подробно разобрано множество примеров (в частности, из школьной геометрии, точнее, из той части школьной геометрии, которая в школах пропускается). Например, объясняется, как вывести из аксиом, что для всякой прямой найдётся точка, на ней не лежащая. Материалы из этих двух книг вошли в сборник "Апология математики" [27] (вместе с другими статьями, уже более общего характера). И проповедь Успенского имела успех: ему была присуждена премия "Просветитель" (учреждённая Дмитрием Борисовичем Зиминым и фондом "Династия") за 2010 г. в области естественных и точных наук. В стиле самого Успенского и здесь мы видим контраст с тем, что он сам считал математику гуманитарной наукой, а такие науки обычно не относят к естественным.

$\mathrm{K}$ элементам популяризации можно отнести и доклад Успенского и Семёнова на семинаре председателя Госкомитета по науке и технике, заместителя председателя Совета Министров СССР Гурия Ивановича Марчука (в присутствии руководителя семинара), см. [19].

Упомянем ещё один жанр текстов, где выражается отношение автора к чужим работам: отзывы и предисловия. Выше уже говорилось об отзыве В. А. Успенского на диссертацию А. А. Зализняка как о самостоятельной научной работе. Но дело в том, что отзыв этот - совсем не уникален (хотя ситуация, видимо, уникальна). В большинстве случаев Успенский, разбираясь в чьей-то диссертации или обозревая статьи сборника, находил способ для понятного максимально широкому кругу читателей (а особенно - слушателей, когда он был официальным оппонентом) объяснения того, что же, собственно, в работе сделано, в чём смысл и важность этого. В качестве примера можно указать предисловие к сборнику "Математика в современном мире" [31]. Это предисловие само по себе является изложением для очень широкого круга читателей целостного взгляда на роль математики и объяснением того, чем эта уникальная роль определяется. Существенный для читателя критический анализ статей сборника составляет лишь малую часть предисловия Успенского. Сами же статьи оказываются прекрасной иллюстрацией мыслей предисловия (помимо их самостоятельной ценности).

Школьная информатика. Отдельного упоминания заслуживает роль В. А. Успенского в становлении нового школьного предмета - информатики. Можно сказать, что она (информатика как школьный предмет) возникла благодаря объединению трёх научно-образовательных потоков, представленных тремя группами людей, которые создали первый массовый курс - учебник по информатике для всех школ страны [43]. Это - Андрей Петрович Ершов, идеолог, организатор и "пробиватель" школьной информатики в стране, автор лозунга "Программирование - вторая грамотность" (Ершов помнил лекции и семинары Успенского той поры, когда сам Ершов был студентом МГУ). Это - Анатолий Георгиевич Кушниренко и Геннадий Викторович Лебедев, которые внесли в идеологию Ершова практику необыкновенно эффективного обучения программированию основной массы студентов мехмата МГУ, сегодня эта традиция распространилась уже до детского сада. Это - Алексей Львович Семёнов и Александр Ханиевич Шень, сыгравшие существенную роль в создании этого первого учебника и отразившие при этом в своей работе подход Успенского и к математической информатике, и к написанию текстов. 


\section{Заключение}

Резюмируя наше краткое описание, скажем, что Владимир Андреевич Успенский многое совершил и оставил после себя множество обязанных ему учеников, последователей и читателей, которым он сумел в какой-то мере передать свой неповторимый способ мышления, восприятия мира и коммуникации. Мы бесконечно благодарны ему за это.

С.И. Адян, Н.Н. Андреев, Л.Д. Беклемишев, С.С. Гончаров, Ю. Л. Ершов, Ю.В. Матиясевич, Ю. С. Осипов, М. Р. Пентус, В.А. Плунгян, Е.В. Рахилина, В.А. Садовничий, А. Л. Семёнов, С. Г. Татевосов, В. М. Тихомиров, А. Х. Шень

\section{Список литературы}

[1] Страница В. А. Успенского на сайте mathnet.ru: http://www.mathnet.ru/rus/person20219.

[2] Страница В. А. Успенского на сайте кафедры математической логики и теории алгоритмов мехмата МГУ:

http://lpcs.math.msu.su/ ${ }^{\sim}$ uspensky/.

\section{Избранные работы В. А. Успенского*}

[3] "Геометрический вывод основных свойств гармонических функций", $У М H$, 4:2(30) (1949), 201-205.

[4] Общее определение алгоритмической вычислимости и алгоритмической сводимости, Дипл. работа, МГУ, мех.-матем ф-т, М., 1952, 90 с.

[5] Математические беседы, ГИТТЛ, М.-Л., 1952, 288 с. (совм. с Е. Б. Дынкиным); нем. пер.: Mathematische Unterhaltungen. Aufgaben über das Mehrfarbenproblem, aus der Zahlentheorie und der Wahrscheinlichkeitsrechnung, Aulis Verlag Deubner \& Co. KG, Cologne, 1979, 272 pp. (with E. B. Dynkin).

[6] “О вычислимых операциях", Докл. АН СССР, 103:5 (1955), 773-776.

[7] "Системы перечислимых множеств и их нумерации”, Докл. АН CCCP, 105:6 (1955), 1155-1158.

[8] Об операциях над перечислимыми множествами, Дисс. ... канд. физ.-матем. наук, МГУ, мех.-матем. ф-т, М., 1955.

[9] "Вычислимые операции и понятие программы (резюме доклада)", в ст. "Заседания Московского математического общества", УМН, 11:4(70) (1956), 172-176.

[10] "К определению алгоритма", УМН, 13:4(82) (1958), 3-28 (совм. с А.Н. Колмогоровым); англ. пер.: "On the definition of an algorithm", Amer. Math. Soc. Transl. (2), 29 (1963), 217-245 (with A. N. Kolmogorov).

[11] Некоторые приложения механики к математике, Физматлит, М., 1958, 48 с.

[12] " $\mathrm{K}$ вопросу о соотношении между различными системами конструктивных действительных чисел”, Изв. вузов. Матем., 1960, № 2, 199-208.

[13] Лекции о вычислимых функииях, Физматгиз, М., 1960, 492 с.; фр. пер.: Leçоns sur les fonctions calculables, Actualités Sci. Indust., 1317, Hermann, Paris, 1966, $412 \mathrm{pp}$.

\footnotetext{
* Мы приводим краткую библиографию; подробную информацию можно найти на сай$\operatorname{Tax}[1],[2]$.
} 
[14] Треугольник Паскаля, Наука, М., 1966, 34 с.; англ. пер.: Pascal's triangle, Popular Lectures in Math., Univ. Chicago Press, Chicago-London, 1974, vii+35 pp.

[15] “Теорема Гёделя о неполноте в элементарном изложении”, УМH, 29:1(175) (1974), 3-47; англ. пер.: "An elementary exposition of Godel's incompleteness theorem", Russian Math. Surveys, 29:1 (1974), 63-106.

[16] Машина Поста, Наука, М., 1979, 96 с.; англ. пер.: Post's machine, Mir, Moscow, 1983, $88 \mathrm{pp}$.

[17] Теорема Гёделя о неполноте, Наука, М., 1982, 112 с.; англ. пер.: "Gödel's incompleteness theorem", Theoret. Comput. Sci., 130:2 (1994), 239-319.

[18] Нестандартный, или неархимедов, анализ, Знание, М., 1983, 62 с.

[19] "Математическая логика в вычислительных науках и вычислительной практике", Вестн. АН СССР, 56:7 (1986), 93-103 (совм. с А. Л. Семёновым).

[20] Что такое нестандартный анализ?, Наука, М., 1987, 128 с.

[21] Теория алгоритмов: основные открытия и приложения, Наука, М., 1987, 288 с. (совм. с А.Л. Семёновым); англ. пер.: Algorithms: main ideas and applications, Math. Appl., 251, Kluwer Acad. Publ., Dordrecht, 1993, xii+269 pp. (with A. Semenov).

[22] “Алгоритмы и случайность", Теория вероятн. и ее примен., 32:3 (1987), 425-455 (совм. с А.Н. Колмогоровым); англ. пер.: "Algorithms and randomness", Theory Probab. Appl., 32:3 (1987), 389-412 (with A. N. Kolmogorov).

[23] "Может ли (индивидуальная) последовательность нулей и единиц быть случайной?", УМН, 45:1(271) (1990), 105-162 (совм. с А. Л. Семёновым, А. Х. Шенем); англ. пер.: "Can an individual sequence of zeros and ones be random?", Russian Math. Surveys, 45:1 (1990), 121-189 (with A. L. Semenov, A. Kh. Shen').

[24] "Mathematical metaphysics of randomness", Theoret. Comput. Sci., 207:2 (1998), 263-317 (with An. A. Muchnik, A. L. Semenov).

[25] Что такое аксиоматический метод?, НИЦ "Регулярная и хаотическая динамика", Ижевск, 2001, 96 с.

[26] "Четыре алгоритмических лица случайности", Матем. просвещение, сер. 3, 10, МЦНМО, М., 2006, 71-108.

[27] Апология математики, Амфора, СПб., 2009, 554 с.

[28] Простейшие примеры математических доказательств, МЦНМО, М., 2009, 56 с.

[29] Колмогоровская сложсность и алгоритмическая случайность, МЦНМО, М., 2013, 575 с. (совм. с Н.К. Верещагиным, А. Шенем); англ. пер.: Kolmogorov complexity and algorithmic randomness, Math. Surveys Monogr., 220, Amer. Math. Soc., Providence, RI, 2017, xviii+511 pp. (with A. Shen, N. Vereshchagin).

[30] Труды по нематематике, В пяти книгах, 2-е изд., испр. и доп., ОГИ, "Математические этюды", М., 2014; т. 2: Философия, 566 с.; т. 3: Языкознание, 2013, 711 с.; т. 4: Филология, 2012, 591 с.; т. 5: Воспоминания и наблюдения, 2018, 1118 с.

\section{Публикации, в подготовке которых участвовал В. А. Успенский}

[31] Математика в современном мире, Сб. пер., под ред. и с предисл. В. А. Успенского, Мир, М., 1967, 202 с.

[32] Х. Роджерс, Теория рекурсивных функиий и эффективная вычислимость, ред. пер. В. А. Успенский, Мир, М., 1972, 624 с.; пер. с англ.: H. Rogers, Jr., Theory of recursive functions and effective computability, McGraw-Hill Book Co., New York-Toronto, Ont.-London, 1967, xx+482 pp. 


\section{Другие цитируемые работы}

[33] А.П. Ершов, В. М. Монахов (ред.), Основы информатики и вычислительной техники, Ч. 1, Просвещение, М., 1985, 96 с.; Ч. 2, 1986, 144 с.

[34] R. M. Friedberg, H. Rogers, Jr., "Reducibility and completeness for sets of integers", Z. Math. Logik Grundlagen Math., 5:7-13 (1959), 117-125.

[35] А. А. Марков, “Теория алгорифмов", Тр. МИАН СССР, 42, Изд-во АН СССР, M.-Л., 1954, 3-375; англ. пер.: А. А. Markov, Theory of algorithms, The Israel Program for Scientific Translations, Jerusalem, 1961, iv+444 pp.

[36] Ан. А. Мучник, "Об основных структурах дескриптивной теории алгоритмов", Докл. АН СCCP, 285:2 (1985), 280-283; англ. пер.: An. A. Muchnik, "On the basic structures of the descriptive theory of algorithms", Soviet Math. Dokl., 32 (1985), 671-674.

[37] J. Myhill, "A fixed point theorem in recursion theory (abstract)", in "Eighteenth meeting of the association for symbolic logic", J. Symbolic Logic, 20:2 (1955), 205.

[38] J. Myhill, J.C. Shepherdson, "Effective operations in partial recursive functions", Z. Math. Logik Grundlagen Math., 1 (1955), 310-317.

[39] H. G. Rice, "Classes of recursively enumerable sets and their decision problems", Trans. Amer. Math. Soc., 74:2 (1953), 358-366.

[40] H. G. Rice, "On completely recursively enumerable classes and their key arrays", J. Symbolic Logic, 21:3 (1956), 304-308.

[41] H. Rogers, Jr., "Gödel numberings of partial recursive functions", J. Symbolic Logic, 23:3 (1958), 331-341.

[42] А. Шень, “Аксиоматический подход к теории алгоритмов и относительная вычислимость", Вестн. Моск. ун-та. Сер. 1. Матем., мех., 1980, № 2, 27-29; англ. пер.: A. Shen, "Axiomatic approach to the theory of algorithms and relativized computability", Moscow Univ. Math. Bull., 35:2 (1980), 29-32.

[43] А.А. Зализняк, Русское именное словоизменение, Наука, М., 1967, 372 с. 